\title{
TRANSFIGURACIÓN DEL SUFRIMIENTO EN EL PENSAMIENTO DE E.M. CIORAN
}

\section{TRANSFIGURATION OF SUFFERING IN THE THOUGHTS FROM E.M. CIORAN}

\author{
Juan $M^{\mathrm{a}}$ DE LAS HERAS NOTARIO \\ $U N E D^{*}$
}

\begin{abstract}
Resumen: En el presente trabajo vamos a otear el paisaje de la fatalidad que, sin duda, representan los escritos de Cioran, con el objetivo de analizar si es posible una solución afirmativa, al estilo de la música y el arte en Schopenhauer o el vitalismo de Simmel, a la esencia problemática de la existencia humana, lo que significa tratar de dilucidar acerca de si es posible la liberación del sufrimiento en el sujeto o, en caso de no serlo, ver en qué medida podemos mitigar el dolor adoptando otro tipo de filosofías de orden terapéutico (epicureísmo, filosofías orientales, etc.) frente a otro tipo de filosofías de carácter pesimista que abogan por la negación de la vida como es el caso de la filosofía de la redención de Mainländer.
\end{abstract}

\section{Palabras clave: Dolor, Conciencia, Transfiguración, Música, Vacío, Vitalismo}

AвSTRACT: In this paper we are going to look at the landscape of the fatality which, undoubtedly, Cioran's writings represent, with the aim of analyzing whether affirmative answer, such as the style of music and art in Schopenhauer or the vitalism of Simmel, to the problematic essence of human existence, is possible. This means trying to elucidate whether liberation from suffering in the human being is possible or, if not, to what extent we can mitigate pain by adopting other types of therapeutic philosophies (epicureanism, oriental philosophies, etc.), opposed to other types of pessimistic philosophies that advocate the denial of life, as is the case with Mainländer's philosophy of redemption.

Keywords: Pain, Conscience, Transfiguration, Music, Emptiness, Vitalism.

\footnotetext{
* Investigador en formación de la EIDUNED, Madrid, España, e-mail: jdelasher3@alumno. uned.es
} 


\section{Introducción}

La dificultad que encontramos al analizar el mencionado paisaje es la ausencia de una estructura arquitectónica que sea capaz de proporcionar unidad sistemática a un entramado de ideas a fin de construir un ensamblaje similar al de los grandes relatos. Cioran es un autor que no ha podido dejar de soslayar cómo los ideales de la modernidad se han ido desmoronando a medida que crecía la crisis de la razón moderna; por consiguiente, el sistema no forma parte de su entramado intelectual; al contrario, su estilo es rapsódico y fluctuante, sus fragmentos y aforismos adoptan múltiples direcciones, ora rizomáticas, al más puro estilo deleuziano, ora caóticas, en función del humor del momento y del estado fisiológico del cuerpo. Ninguna dirección en su pensamiento es desdeñable y ninguna goza de privilegios frente a las demás; todas, aunque diferentes y a menudo contrapuestas, son válidas, pues forman parte de un legado intelectual siempre abierto a nuevos horizontes hermenéuticos.

\section{Itinerario de la Liberación}

El sentido de una filosofía de la liberación que se precie ha de partir de la ecuación existencia-sufrimiento, ecuación derivada de todas las experiencias del sujeto. El sufrimiento anida en la vida pues existimos en tanto que sufrimos. Una merma de sufrimiento implica una merma de existencia y una minoración del ser. Ante esta tesitura, cabe preguntarnos si es deseable la liberación del sufrimiento a costa del triunfo de la nada frente al ser. La liberación preocupa a quienes, conscientes de la condición dolorosa de la vida, en un acceso de lucidez han despertado en su interior el sentimiento metafísico de la existencia. Inmersos en la dialéctica de la subjetividad, la liberación debe proceder de sí mismos, de una conversión interior. De poco sirven las teorías que no emanan de nuestras profundidades. Adoptar doctrinas orientales, en las que la idea y el acto se fusionan formando una identidad de salvación y renuncia que violentan nuestra condición de libertad, es una solución que, irónicamente, a menudo en vez de liberar, condenan a quienes la adoptan a una existencia anodina sustentada por una sensibilidad mortificada.

Frente a este tipo de filosofías, Cioran elogia la filosofía del caído del tiempo, es decir del mendigo militante que ya no soporta la vida en sociedad y, en un acceso de lucidez, opta libremente por seguir un estilo de vida totalmente alejado de la acción, como alternativa a una vida sometida al tiempo, al agobio y a la tre- 
pidación, situaciones que no dejan de ser cadenas impuestas por la modernidad. Véase el siguiente extracto relativo a la ética del mendigo militante:

Él, al menos, ni miente ni se miente: su doctrina, si la tiene, la encarna él mismo; no le gusta el trabajo y lo prueba; como no desea poseer nada, cultiva su desprendimiento, condición de su libertad. Su pensamiento se resuelve en su ser y su ser en su pensamiento. Está falto de todo, es él mismo, dura. Estar a la altura de la eternidad es también vivir al día. Para él, los otros están encerrados en la ilusión [...]. Su pereza, de una rara calidad, hace de él un auténtico "liberado", perdido en un mundo de bobos y engańados ${ }^{1}$.

Con la renuncia al imperio de los actos, el mendigo expande la esfera de la conciencia, pues ésta, piensa Cioran, mengua con la acción. Sin embargo, nos enfrentamos a la tesitura de si esta praxis supone una verdadera fuente de liberación, pues si la irrupción de la conciencia supuso en los orígenes la irrupción del sufrimiento, ¿cómo podría la expansión de su esfera, de manera paradójica, liberar o, al menos, minimizar el dolor de ser? Cioran insiste en que para recobrar la libertad es imprescindible adoptar una terapéutica del desapego, alimentada por la experiencia del vacío:

Deponer el fardo de la sensación, no reaccionar ya al mundo por medio de los sentidos, romper nuestros lazos. Empero, toda sensación es lazo, el placer tanto como el dolor, la alegría como la tristeza. Sólo se libera el espíritu que, puro de todo contubernio con seres u objetos, se ejerce en su vacuidad ${ }^{2}$.

Si la vida acarrea tristeza, desesperación y llanto, un alma grande asume estos sentimientos como escalones de la transfiguración, en un proceso ascensional hacia un estado de pureza, un estado de desapego de la materia en el que fluye la vida de manera dulce e inmaterial. Se trata de realizar un proceso transformador del dolor en el que nuestra infelicidad pasa a ser un estado creador, altamente productivo y fecundo. Vivir la vida de manera profunda e intensa, más allá del límite:

${ }^{1}$ Cioran, E.M. (2000). La tentación de existir, Madrid: Taurus, p. 12.

${ }^{2}$ Ibid., p. 14. 
Más allá de la esfera habitual de las experiencias vitales existe una zona en la que tiene lugar una especie de sucesión de transfiguraciones. El sufrimiento se convierte en alegría; la alegría en sufrimiento; el entusiasmo en desilusión y la desilusión en entusiasmo; la tristeza en ardor y el ardor en tristeza. La consistencia de los estados anímicos desaparece en esa sucesión de transfiguraciones ${ }^{3}$.

Aquí Cioran aboga por un vitalismo radical, espiritual y no materialista, como terapéutica transfiguradora del sufrimiento. Vivir la vida con gran intensidad, sobrevolar por encima de las cosas, transcender su materialidad y desapegarse de los entes, son máximas de una ética de la transfiguración. Alcanzar el espacio de las grandes conversiones sólo resulta accesible durante el éxtasis de las propias vivencias y después de haber padecido mucho, ya que el dolor, acompañado del sentimiento interior de la muerte, confiere profundidad a los actos de la vida. No importan las causas del sufrimiento, vengan de donde vengan, ya sean causadas por el hombre, la enfermedad o una pérdida irreparable. Sea un dolor transitorio o el dolor esencial de la existencia, da igual, lo importante es su utilidad para fecundar el interior del sujeto, para que los actos de la vida adquieran esplendor y profundidad, y eleven al hombre al espacio de las grandes transfiguraciones.

En Cioran, hay dos vías que pueden ser utilizadas para trascender el dolor: una, integrándolo en nuestro organismo mediante un proceso de des-extrańamiento e interiorización, es decir, un proceso de asimilación inmanente en nuestro cuerpo; esto significa considerar el sufrimiento como un acontecimiento normal y perfectamente natural, algo con lo que tenemos que lidiar a lo largo de nuestra existencia, pues, nos guste o no, forma parte de la esencia de la vida. La actitud a adoptar es la siguiente: si no puedes vencer a tu enemigo, el dolor, hazte amigo de él, acógelo en tu seno y transfórmalo. Otra vía es intentar, por un esfuerzo interno, elevarnos por encima del nivel donde se mantiene el dolor en nuestro organismo y nuestra conciencia. La primera vía — la más fácil y por ello la más frecuente - tiene por objeto la asimilación del sufrimiento, la anulación de la conciencia del dolor y la pérdida de su sustancia para, finalmente, arrojarlo a las profundidades del olvido: «la única salvación posible es el olvido. Me gustaría poder olvidarlo todo, olvidarme a mí mismo y olvidar el mundo entero [...]. Si me obligasen a tener una esperanza, sólo podría ser la del olvido absoluto» ${ }^{4}$.

${ }^{3}$ Cioran, E.M. (1996). El libro de las quimeras, Barcelona: Tusquets, p. 72.

${ }^{4}$ Cioran, E.M. (1996). En las cimas de la desesperación, Barcelona: Tusquets, p. 88. 
La segunda vía requiere un enardecimiento de la voluntad, algo inabordable para quienes no hayan experimentado una fuerte tensión interior y hayan alcanzado las cimas de la desesperación. Por esta vía, para que el dolor y la enfermedad no extenúen a la conciencia, es necesario que, por medio de una infinita tensión, nos elevemos por encima de su nivel hasta alcanzar un nivel superior, desde cuya altura podamos dominarlo como un simple proceso natural. Alcanzar un estadio de exacerbación de la conciencia en la que se intensifican las pulsaciones de la vida. Todo reside en alcanzar un nivel de conciencia superior al del dolor: «En el punto culminante de una crisis, apretar los puños, tensar los nervios, tener una voluntad de afirmación orgánica, un pálpito trepidante como el producido por un rayo del ser, nos salvan y nos fortalecen como un baño balsámico" ${ }^{5}$.

Finalmente, al tener que, inexorablemente, habérnoslas con el dolor, de lo que se trata es de volver fecunda esa maldición, de extraer de su sustancia lo que no somos capaces de extraer de una infinidad de felicidades. Sólo así el desfallecimiento producido por el sufrimiento podría llegar a ser una transfiguración. Aprovechemos pues, todos los instantes en que el dolor y la enfermedad de la vida abrasa nuestro yo, en los que el sufrimiento se incuba en nuestro ser con el objeto de aminorarnos y reducir nuestra materia a pequeños restos de existencia, interminables pesadumbres que poco a poco van royendo nuestro espíritu. No le faltan motivos al filósofo para plantearse las siguientes cuestiones:

¿Por qué no aprovechar esos momentos para estimularnos en el infortunio, para sacar brillo a la sangre de nuestras heridas, para poner una aureola a nuestros reveses? Si no aprendemos a hacer de la enfermedad algo positivo, ¿por qué seguir viviendo llevando consigo el pesar por una vida perdida? ¿Por qué quejarnos ante un desastre, cuando este podría convertirse en el principio de una serie de iluminaciones? Y todos los sufrimientos que nos han ensombrecido el rostro, ¿acaso no son otras tantas fuentes de nuestra transfiguración? ${ }^{6}$

Y para volver fecundo el dolor y transformarlo en resorte de nuestro dinamismo vital, Cioran piensa que es esencial la intensificación de nuestras vibraciones internas, la sintonía exacerbada de la conciencia con la voluntad para abrir las vías al acceso de un éxtasis vital que desemboque en una gran transfiguración, en un proceso de purificación interna en el que quede sometida la voluntad. A través

${ }^{5}$ Cioran, E.M. (1996). El libro de las quimeras, op. cit., p. 77.

${ }^{6}$ Ibid., op. cit., p. 78. 
de esta dinámica transformadora, Cioran se enfrenta al sufrimiento existencial adoptando una salida positiva, de ningún modo pesimista, sino al contrario, una vía de corte vitalista, heredada de Simmel, cuya finalidad de la vida es trascenderse a sí misma (Simmel, 2004). La esencia de la vida es concebida como la capacidad que tiene ella misma para autotrascenderse, para ir más allá de sí misma. En este sentido, la vida es un constante devenir, un incesante producir algo que se vuelve en contra, que se le enfrenta y le hace superarse. Un plus vital que nos impulsa a rebasar nuestros límites. En esta línea de pensamiento, Cioran afirma que el dolor puede transcenderse por medio de su transfiguración, a través de unas vibraciones internas que conducen a una serie de éxtasis vitales:

Que el éxtasis sea la medida de nuestra vibración y sus cimas nuestra patria. Que gritos de desesperación y chirridos causados por el crujir de dientes producto del odio sea lo que dé intensidad a esas vibraciones y que todos los lamentos se transfiguren en su entusiasmo. Sumerjámonos en el dolor hasta que se vuelva música y que la enfermedad cante su renuncia en himnos ${ }^{8}$.

Trascender el dolor a través del éxtasis vital equivale, en Cioran, a la solución de la dialéctica dolorosa de la existencia: la serenidad del espíritu (tesis) se enfrenta continuamente al dolor vital (antítesis) y su transfiguración busca el desprendimiento inconcluso de la conciencia (síntesis), tal es la dialéctica dolorosa inmersa en todos los ámbitos de la vida. Por tanto, la transfiguración del dolor se convierte en el objeto final de la ética, trascender el ser sufriente para despojarle del sufrimiento y así dar paso al existente liberado. Pero, para que se produzca semejante conversión, el sufriente ha de entablar una lucha encarnizada a favor del abandono de sí mismo y la rebelión contra el sometimiento a la inercia de su propio vivir, una lucha contra su propio tiempo y el acomodo en la temporalidad. El anhelo de las últimas transfiguraciones ha de instalarse en su conciencia. La voluntad ha de enardecerse y la sensibilidad exacerbarse con el objeto de que la transfiguración del dolor de la vida se convierta en la única obsesión de su existencia, en la máxima fuente de su entusiasmo vital para que el ímpetu de vivir sea irresistible y las brasas de la desesperación, el resorte de la voluntad.

\footnotetext{
${ }^{7}$ En torno a la autotrascendencia de la vida, léase la filosofía vitalista de Simmel. Simmel, G. (2004). Intuición de la vida, La Plata (Argentina): Terramar Ediciones.

${ }^{8}$ Cioran, E.M. (1996). El libro de las quimeras, op. cit., p. 79.
} 


\section{La salvación en la música}

Relata Cioran en sus Conversaciones que, de entre todas las artes, la música es la que ha desempeñado el papel más significativo en su vida, pues sin ella, ésta carece de sentido9. En verdad la música penetra en lo más profundo de nuestro ser, afecta a lo más íntimo de nuestra personalidad, amansa a la fiera que todos llevamos dentro, calma nuestros furores y nos traslada a un mundo de serenidad y sosiego en el que el dolor, transitoriamente, se desvanece. No es extraño que en Cioran hiciera mella el sentimiento musical de la existencia y considerara, por tanto, la música como la primera etapa en el itinerario de la liberación, en el sendero hacia un acercamiento a la divinidad. Pues, en el éxtasis musical el sujeto pierde la materialidad, la pesada petrificación del cuerpo y se funde en armonías y vibraciones interiores al experimentar un estado de beatitud y serenidad de aérea irrealidad, en el cual, el dolor de ser ha desaparecido.

A través de la música, el sujeto rompe las barreras de la individuación, las condiciones limitativas impuestas por la existencia del mundo y se funde en él bajo la acción de la suprema voluntad de unidad. En el éxtasis musical, el sujeto experimenta la unidad genuina del yo con el mundo, el ser se transfigura en melodía al perder su pesada materialidad, y el espíritu abandona transitoriamente su identidad actual para volver a su identidad originaria anterior al proceso de individuación. El estado estético musical carecería de valor si no anulara la conciencia de nuestra limitación impuesta por las condiciones espacio-temporales de la existencia, la fatalidad de nuestra limitación espacial y temporal. Sufrimos por no poder volvernos inmateriales y puros. La pesada materialidad nos aísla, nos encadena al mundo como objetos, y el sujeto percibe dolorosamente cuál es el sustrato que le liga a la tierra. Por tanto, el estado estético musical implica una transfiguración de los estados depresivos, del sufrimiento y de las tristezas íntimas, que pierden su carácter de pesada materialidad al purificarse con las vibraciones musicales. En el éxtasis musical, la sensibilidad se agudiza, la voluntad se enardece y la conciencia se dilata surgiendo una gran experiencia de unicidad universal, un estado límite de intensas vibraciones, de sensaciones únicas, con las que se toma conciencia de haber alcanzado las cimas de la intensidad vital. El dolor desaparece en el estado de máxima embriaguez musical, mostrando una armonía absoluta y una reconciliación del yo con la existencia. Así, la música nos abre las puertas a un mundo nuevo, un mundo sin dolor, más anhelado por quienes han sufrido más en la vida que por aquellos que han mantenido una

\footnotetext{
${ }^{9}$ Cioran, E.M. (1996). Conversaciones, Barcelona: Tusquets, p. 211.
} 
existencia sosegada. La música nos aleja del mundo. Ese alejamiento implica una pérdida de vitalidad en aras de un mundo de resonancias trascendentes y de serenidad eterna, es la aspiración a la que induce la música de un Mozart o un Bach; un remedio contra la desesperación originada por el dolor de ser, pues la música despierta el anhelo de evadirnos del mundo, del olvido de la caída dramática en el tiempo y la nostalgia del paraíso perdido. La presión del sufrimiento despierta la ańoranza de trascender el mundo y de elevarnos hacia la conquista de los cielos, de otros mundos de pureza y serenidad. Véase la belleza con la que expresa Cioran esta idea:

Con Bach nos elevamos dramáticamente hacia las alturas. Quien en el éxtasis de esta música no haya sentido lo transitorio de su condición natural y no haya vivido la serie de mundos posibles que se interponen entre el paraíso y nosotros, no entenderá por qué sus tonalidades están constituidas por besos de ángeles ${ }^{10}$.

La música de Bach, piensa Cioran, despierta en el alma humana el recuerdo del paraíso, su pathos es representar el proceso de ascensión a la eternidad. Pero no una eternidad como la concebida tradicionalmente por la cultura cristiana como una infinidad de instantes, sino como un instante eterno, absoluto, inmanente en el tiempo, sin centro y sin límites, en el que todo es actual, es decir, un eterno presente sin devenir. Si Bach nos catapulta al paraíso, Mozart nos introduce en él. La serenidad, la trasparencia y la pureza de la música de Mozart, junto al esquema formal de felicidad que revelan sus armonías llevaron a nuestro filósofo a catalogar la música de Mozart como la música oficial del paraíso, revelación del ser redimido del dolor. La música pura y aérea de Mozart nos transporta a un mundo inmaterial, donde el entusiasmo se convierte en vuelo y la alegría sustituye a la tristeza. Un estado de suspensión del dolor e inundación de felicidad en el que la conciencia planea sobre sí misma. Toda su obra es un canto a la alegría, un anhelo de escapar del mundo y alcanzar el paraíso, un enmascaramiento de los sufrimientos de la caída en el tiempo; un sueño de juventud que duró hasta el último año de su vida, cuya alegría se vio empañada en sus últimas composiciones inundadas de tristeza sombría y muerte. El final de su vida significó un descenso de los cielos, el despertar del sueño de toda una vida de entusiasmo celestial, un reencuentro con la condición humana, el tránsito fatal desde una atmósfera trascendente a otra atmósfera de podredumbre. La caída de Mozart representa para Cioran una revelación, un desprendimiento

${ }^{10}$ Cioran, E.M. (1996). El libro de las quimeras, op. cit., p. 103. 
de la condición originaria del ser, un despertar de la conciencia engañada, la afirmación del dolor y el confinamiento del paraíso en las profundidades del yo, el desvelamiento, aunque tardío, de la fatal condición humana impuesta por la individuación.

\section{La terapéutica del desapego}

La terapéutica del desapego pretende encontrar una vía de liberación por medio del abandono de la fuente de todas nuestras servidumbres, el apego a los entes, las cosas, las personas y la vida. Para ello es preciso concebir la irrealidad de todo lo existente, concebir el ente como un simple agregado, el lugar de encuentro de algunos elementos asociados de manera transitoria, o bien, en términos heideggerianos, comprender el yo de manera provisional. Concebir el yo como una forma de asociación estructural de unos elementos que no mueren, que no se diluyen en la nada, sino que se disgregan para adoptar una nueva forma de asociación, un nuevo ente, una nueva vida, un nuevo yo que ya no es nuestro yo, sino otro "yo" u otro "eso". Cioran plantea la problemática que conlleva la vía del desapego. El apego a los seres procede de nuestro temor al no-ser, el temor a la nada. Nos sentimos más tranquilos apegados a los seres que desvinculados de ellos, nos sentimos sosegados y liberados del temor a la nada, sin darnos cuenta del encadenamiento al que poco a poco nos vamos sometiendo, pues la estructura existenciaria de nuestro ser en el mundo, apoyada sólidamente en nuestra sensibilidad nos hace estructuralmente vulnerables al apego de los entes. Heidegger concibe el apego a los entes intramundanos como una caída o estado de yecto del ser-ahí del que no podemos desvincularnos por ser este estado un elemento óntico de su propia estructura existencial ${ }^{11}$ (Heidegger, 1973). Cioran concibe la liberación como una segunda caída en términos heideggerianos o una vuelta hacia atrás, como un caer del mundo o una fuga del ser-ahí hacia sí mismo, esto es, un desapego del ser-ahí del mundo o un abandono de los entes intramundanos. Ver cada ser, cada ente como un accidente, desligarse del ser e, incluso, de nosotros mismos, persuadirnos de la irrealidad de las cosas, concienciarnos de que carecemos de existencia intrínseca, éstas son máximas para desarrollar una ética del desapego, una vía de liberación y una terapéutica contra el dolor. La vía del desapego, en consecuencia, resulta ser un itinerario hacia la soledad o ensimismamiento, una soledad no amarga, pues no procede de nuestros fracasos,

\footnotetext{
${ }^{11}$ Para la temática en torno a la estructura existencial del "ser ahî": Heidegger, M. (1993). Ser y tiempo, Barcelona: Planeta-De Agostini.
} 
sino de nuestras renuncias, resultado de una insistente toma de conciencia en la que el yo es la víctima.

Para Cioran, la verdadera liberación no puede concebirse sin haberse liberado de la libertad misma, es decir, la auténtica liberación procede de la imprescindible disociación de la acción y el deseo. Sin embargo, Cioran es consciente de la dificultad que implica semejante proceso. El deseo rara vez desaparece, es indesarraigable y, por ende, es un elemento ontológico que forma parte de la estructura existencial de ser del ser-ahí. Un combate contra el deseo conlleva la angustia del ser en el mundo, una angustia impresa por la realidad óntica del ser-ahí que dificulta su transfiguración en una alegría neutra. Semejante transfiguración abre las puertas al estado "alegre y sin alegría» preconizado por las Upanishad, un estado que se alcanza tanto por la vía de la afirmación como por la negación de un principio supremo, la vía del ser o la vía de la nada. Ambos itinerarios coinciden en la experiencia final: en el abandono del apego del serahí a los entes intramundanos para regresar a un estado de ensimismamiento, es decir, a un deslizamiento fuera del mundo de las apariencias. Si en Heidegger el estado de apertura del ser-ahí implica la caída en la unicidad y el mundo, esta caída no es más que una fuga del ser-ahí ante sí mismo por temor a la soledad del estado de su propio ensimismamiento, es decir, un des-ensimismamiento y, por ende, un apego a las apariencias intramundanas. El desapego significa, por tanto, el proceso inverso a la caída heideggeriana o la cura existenciaria estipulada en Ser y tiempo. En este sentido ontológico-existencial, prescindiendo de cualquier estímulo intramundano y por el solo en sí de la existencia, se manifiesta Cioran, transfigurando la angustia inherente a la onticidad del ser-ahí en una alegría neutra:

Que uno se disuelva en lo absoluto o en lo vacío, en los dos casos lo que se alcanzará es una alegría neutra: alegría sin determinación alguna, tan desnuda como la ansiedad, cuyo remedio se pretende, y de la que no es más que el desenlace, la conclusión positiva ${ }^{12}$.

Por otra parte, esta alegría se presenta ligada al comprender, lo que se convierte en un problema hermenéutico con referencia al concepto de verdad, pues toda comprensión tiene como fin la interpretación de la realidad de manera correcta, lo cual requiere un estado de apertura hacia los entes para captar su verdad. Y este estado de apertura es, según Heidegger, un elemento esencial de la estructura del

${ }^{12}$ Cioran, E.M. (2000). El aciago demiurgo, Madrid: Taurus, p. 55. 
ser-ahí que evita la arbitrariedad del subjetivismo, en aras de un conocimiento objetivo. Desde esta concepción heideggeriana de la comprensión, Cioran se permite hacer la siguiente afirmación: «Cuando se ha comprendido que nada es, que las cosas no merecen ni siquiera el estatuto de apariencias, ya no se necesita ser salvado, se está salvado y desdichado para siempre» ${ }^{13}$.

Si el conocimiento de la realidad adquiere el estatuto de conocimiento objetivo en el descubrir la esencia de los entes, si los entes se muestran libremente y el comprender del ser-ahí aprehende lo que los entes muestran, entonces la verdad del aforismo anterior denota la insignificancia de las cosas, el sinsentido del apego a los entes intramundanos y la angustia del ser-ahí frente a la desdicha originada por el ser en el mundo. Para Cioran, el estado de liberación requiere del ser-ahí una manera de estar en el mundo libre de los influjos de los entes, los cuales ni siquiera adquieren el estatuto de apariencias; esta liberación implica la renuncia y el desapego. Sin embargo, esta tarea se muestra violenta con la estructura esencial del ser-ahí, pues el estado de yecto y la caída del ser-ahí son elementos existenciarios ineludibles que se adquieren al nacer:

Si el apego es un mal, hay que buscar su causa en el escándalo del nacimiento, pues nacer es apegarse. El desapego debería, pues, aplicarse a hacer desaparecer las huellas de ese escándalo, el más grave y el más intolerable de $\operatorname{todos}^{14}$.

El ideal sería perder, sin sufrir por ello, el gusto por los seres y las cosas. Cada día nos haría falta honrar a alguien, criatura u objeto, renunciando a él. Llegaríamos así, tras recorrer las apariencias y despedirlas una tras otra, al perpetuo desestimiento, al secreto mismo de la alegría ${ }^{15}$.

El desapego requiere la renuncia consciente y deliberada de los seres, un proceso de distanciamiento progresivo de las cosas hasta llegar a alcanzar la indiferencia total hacia los entes intramundanos, una mortificación progresiva de la sensibilidad en aras de la erradicación de los deseos; un proceso no menos heroico que dramático, pues en realidad no renunciamos, sino que queremos renunciar, de ahí la heroicidad de la renuncia. El acto de la renuncia se presenta disociado del deseo de la renuncia, pues, en realidad, ¿estamos a la altura moral

\footnotetext{
${ }^{13}$ Ibid., p. 68.

${ }^{14}$ Cioran, E.M. (1995). Del inconveniente de haber nacido, Madrid: Taurus, p. 23.

${ }^{15}$ Cioran, E.M. (2000). El aciago demiurgo, op. cit., p. 84.
} 
para afrontar el sacrificio exigido por la renuncia? La renuncia requiere sacrificio para transfigurar la vida, desprenderse de todo para convertirse en centro metafísico, concebir la renuncia como un elemento positivo dentro de la estructura existencial del ser del ser-ahí. De esta manera, la renuncia es transfigurada en una ganancia: renunciar para convertirnos en el centro metafísico o la fuente vital del ser. Sólo así la renuncia deja de ser una pérdida para transformarse en una forma de amor de gran fecundidad, abierta a la vida, abierta al mundo. Alcanzar un gran amor a través de la renuncia, pues cuando ya no tenemos nada es cuando lo tenemos todo:

Sólo hay una forma por la que aún la renuncia puede llegar a ser fecunda: si está abierta hacia la vida. Una vez rotos los lazos con el mundo, tengamos el suficiente amor como para, desde nuestro distanciamiento, poder abarcarlo todo; situémonos infinitamente lejos de todo e infinitamente cerca de todo; englobémoslo todo con una visión de éxtasis. De esta manera la renuncia significará una ganancia. En ella nuestra alma se abrirá a todo, porque lo habrá perdido todo. Un amor total e infinito no es posible sin distanciamiento ${ }^{16}$.

Ahora bien, ¡cómo compaginar la transfiguración de la renuncia con el apego a la voluntad de un yo que se despliega en el mundo de la diversidad desligado completamente del mundo de la identidad? De nada sirve que sometamos el mundo a nuestra voluntad, mientras no hayamos triunfado sobre el tiempo seguiremos siendo esclavos de la diversidad. La civilización nos enseña y conmina a dominar y apoderarnos de los entes intramundanos. Mediante la praxis de la dominación nos apoderamos de las cosas y nos consideramos sus dueños y señores, pero en realidad nos convertimos en sus esclavos. Cada nueva adquisición se convierte en un eslabón más de la cadena. El yo que se eleva por encima de los demás es menos libre que ellos, se encadena a sus facultades y talentos, y presa de sus ambiciones se aleja de su salvación. Por ende, la salvación sólo es posible cuando se alcanza la victoria sobre el tiempo, cuando el yo toma conciencia de la necesidad de la renuncia como vía de liberación. A través de la renuncia, el desapego y la negación de los actos, el ser-ahí pretende desligarse del mundo de la diversidad para unirse al mundo de la unicidad. La heroicidad de este tránsito radica en la dificultad y el esfuerzo titánico que ha de realizar el ser-ahí para exiliar a su yo de sí mismo, para enajenarse de su bien más preciado, pues, de hecho, el yo es el elemento existenciario esencial de la estructura del ser-ahí.

${ }^{16}$ Cioran, E.M. (1996). El libro de las quimeras, op. cit., p. 67. 
¿Cómo avanzar, pues, por la vía de la renuncia y el desapego?, ¿cómo es posible la liberación de la influencia de nuestro yo sin sufrir la depresión de los estados melancólicos? Avanzar en el desapego, nos dice Cioran, es privarnos de las razones del yo que nos seducen para actuar, es hundirnos en un estado de melancolía propiciada por la desaparición de los deseos, es precipitarnos en la indiferencia y la neutralidad para situarnos por debajo de la vida y la muerte, en la nivelación de las apariencias y la invalidación de la diversidad. Las consecuencias son desastrosas, pues si todos los entes, sus propiedades y todos los aspectos del mundo son indistinguibles y equivalen a lo mismo, eso explica la imposibilidad de tomar una elección. Neutralizada la diversidad, el ser-ahí se hipostasía en el Uno, vive en medio de una enajenada irrealidad, de una pesada indiferencia. Ahora, bajo la monotonía de la unicidad, la inexistencia de las cosas le pesa. El Uno le oprime y le arrastra a la impropiedad. Para retroceder ha de despertar, tomar conciencia de ello y desapegarse del Uno. A través de este comprender, el ser-ahí siente necesidad de realizarse, de respirar en lo múltiple, se ensaña contra el espíritu de desinterés que le ha llevado a la erradicación de los actos y concibe la salvación bajo el engaño de las apariencias, la afiliación a lo múltiple y su hundimiento en el yo:

Realizarse es entregarse a la embriaguez de lo múltiple. En el Uno nada cuenta sino el Uno mismo. Rompámoslo, pues, si deseamos librarnos del maleficio de la indiferencia, si queremos que toque a su fin la monotonía en nosotros y fuera de nosotros ${ }^{17}$.

En última instancia, el ser-ahí, desengañado de la diversidad y del Uno al mismo tiempo, concibe la destrucción de la indiferencia como la última etapa hacia la indiferencia par excellence: «El último paso hacia la indiferencia es la destrucción de la idea misma de indiferencia» ${ }^{18}$.

\section{La purga de la conciencia y la experiencia del vacío}

En Cioran encontramos dos concepciones del vacío. Por un lado, el tedio o vacío negativo y, por otro, lo que los budistas llaman shunyata o el vacío como experiencia metafísica, este es el vacío positivo. El tedio proporciona una conciencia del tiempo como un tiempo hipostasiado, un tiempo que, detenido,

${ }^{17}$ Cioran, E.M. (1993). La caída en el tiempo, Barcelona: Tusquets, p. 145

${ }^{18}$ Cioran, E.M. (1995). Del inconveniente de haber nacido, op. cit., p. 164. 
ha dejado de ser tiempo. Un tiempo que no corre y carece de objeto. Es el tedio rayano en la desesperación. Si, para Heidegger, el tedio aparece con la percepción de lo existente en la temporalidad dinámica y evolutiva del ser-ahí, en Cioran el tedio es la percepción de lo existente en una temporalidad estática, congelada, absolutamente paralizada. La percepción de cómo el tiempo se desprende de la existencia y se disgrega la unidad orgánica que forman ambas entidades. En la vida avanzamos con el tiempo, somos tiempo; en el tedio ya no estamos en el tiempo, éste se separa de la existencia, se exilia fuera de nuestro mundo. Sin embargo, el vacío como experiencia metafísica, aunque parecido en su exterioridad al tedio, en su interioridad es algo positivo. Es una forma de curarse de todo, una vía de liberación a través de un proceso de purga de la conciencia en el que se eliminan todas las propiedades del ser a fin de alcanzar un estado en el que, en lugar de tener una sensación de carencia, se llega a alcanzar una sensación de plenitud por la ausencia de las condiciones generadoras del dolor, esto es, el vacío como instrumento de salvación o vía de liberación del sufrimiento: la vacuidad o shunyata. El método consiste en liquidarlo todo, no tener ninguna atadura, avanzar en el desapego hasta alcanzar la vacuidad absoluta, un éxtasis vacío, sin contenido y, por tanto, de plenitud o felicidad perfecta. Es el aspecto positivo del budismo tardío de la escuela Madhyamika que tanto ha influido en el pensamiento de Cioran.

El sufrimiento es el factor más influyente y determinante de nuestro ser en el mundo. Son nuestros sufrimientos los que dan peso a nuestros actos y a nuestros pensamientos. Nos dice Cioran, que son ellos también los que «nos hacen proclamar que no hay realidad en ninguna parte, que ni ellos son reales. De este modo, nos sugieren una estratagema de defensa: triunfamos sobre ellos declarándolos irreales, refiriéndolos a la engañifa general» ${ }^{19}$. Por tanto, si todo es irreal, si no hay nada esencial, entonces la vacuidad, en tanto ausencia de sufrimiento, colma los instantes de indiferencia y felicidad. En consecuencia, el método consiste en desenmascarar la realidad para percibir en los entes la no realidad, la condición de agregados que se esconde tras ellos, como encuentro transitorio, si no azaroso de los elementos simples que componen la materia. Desvelar que los seres no son sino meras apariencias, ensamblajes fugitivos de elementos que no esperan más que disgregarse tras la muerte. De ahí la necesidad de salvación, ya que ésta no tiene sentido más que en la provisionalidad de la sustancia. Este despertar o comprender la realidad despoja al ser de todos sus atributos. Deja de ser fundamento, apoyo, lugar de nuestros apegos, sosiego de la conciencia, pues,

${ }^{19}$ Cioran, E.M. (2000). El aciago demiurgo, op. cit., p. 76. 
en realidad, no hay ser sino un simulacro de ser. Sin el ser ya no hay servidumbre; todo acontecimiento y lazo es inesencial.

Despojados del prejuicio del ser, se nos abre una vía de liberación. El pensamiento, al igual que el deseo, es prejuicio y traba, de los cuales es preciso desprenderse. La purga de la conciencia implica la liberación de la vorágine del pensamiento, de ese proceso indefinido y vicioso, tortura del yo, en el que el ser-ahí se desemboza sojuzgado. La transfiguración del sufrimiento, por tanto, comienza con la rotura de los mecanismos del deseo y del pensamiento. Ambos se nutren de su propia sustancia, les es inherente la manifestación, la multiplicación y el ajetreo. La purga de la conciencia nos ayuda a desprendernos de toda idea, de toda traba en el itinerario de la liberación. Desembarazar al espíritu de toda creencia es despojarle de obstáculos para el desistimiento. Sólo se logra elevándonos por encima de las operaciones inherentes al mecanismo del pensamiento y del deseo. Paralizando sus movimientos se desembozan las profundidades del vacío, estado en el que nuestras creencias y deseos, intrínsecamente superficiales, gozan del mismo grado de irrealidad. Con la experiencia del vacío se liquida la aventura del yo al apego del ser, un hundimiento dichoso, lleno de plenitud y alegría, piensa Cioran:

El ideal sería perder, sin sufrir por ello, el gusto por los seres y las cosas. Cada día nos haría falta honrar a alguien, criatura u objeto, renunciando a él. Llegaríamos así, tras recorrer las apariencias y despedirlas una tras otra, al perpetuo desistimiento, al secreto mismo de la alegría ${ }^{20}$.

En las sociedades occidentales, la vida se desarrolla a través de la acción, la planificación y el proyecto. Sin embargo, para el desengañado todo acto es engaño y espejismo, pues lo que importa no es el poseer y el producir, sino comprender y discernir el grado de despertar al que el ser-ahí ha llegado, su capacidad de percibir la irrealidad de los fenómenos. Solo alcanzando la experiencia de la vacuidad se encuentra la ausencia de toda búsqueda, el reencuentro con nuestros orígenes y la eterna virtualidad. Para la sabiduría oriental, la dicha no se encuentra en el deseo, sino en el entusiasmo por la ausencia de deseo, estado de plenitud y alegría completamente extrańo al pensamiento occidental. Influenciado por las filosofías orientales, Cioran entiende que sólo hay verdad y salud en dos entidades existenciarias: el trabajo físico y la contemplación, lo demás carece de realidad, es accidental, inesencial, inútil y malsano. El trabajo físico y

${ }^{20}$ Ibid., p. 84. 
la contemplación son medios para anular la diversidad de los contenidos de la conciencia y precipitarla en lo unitario a fin de alcanzar un estado de conciencia como forma pura, antesala de la ausencia de conciencia, estado pleno de absoluta vacuidad, serenidad y alegría simbolizada por la carismática sonrisa del Buda. Ambos procesos liberan la conciencia de la vorágine del pensamiento y del salto sucesivo de idea en idea en el que se enfrasca el yo en su peregrinaje psíquico. Cioran ve una vía de escape a la vorágine del pensamiento en la anulación de la memoria y la conciencia, un estado de eterna virtualidad y beatitud liberado de las cadenas del deseo, del acto y del pensamiento y, en consecuencia, de su corolario final, el dolor. Esa región de la conciencia sin conciencia en la que ya nada importa, en la que lo negativo se convierte en positivo, en la que ya no hay sí mismo, yo, sujeto o atman. En el reino de la vacuidad, el vacío ocupa el lugar del todo, plenitud positiva de no-realidad. Desengañados de la embriaguez de la ilusoria identidad, el yo deja de satisfacer nuestras exigencias de permanencia, de solidez e intemporalidad; en su lugar se instala el vacío, ese «abismo sin vértigo» que nos proyecta en el orden de la temporalidad y la finitud, tomando conciencia de nuestra frágil condición existenciaria.

No obstante, llegados a este punto, es hora de que nos cuestionemos si la esperada plenitud proporcionada por el vacío es real o no. ¿Y si la ilusión de permanencia inherente a la idea de absoluto en la identidad fuera más reconfortante y consoladora que la de la vacuidad? ¿Puede, en última instancia, el vacío transmutar el sufrimiento en felicidad? ¿No será que el ser-ahí desengañado de la identidad se enfanga en una engañifa mayor, la de la vacuidad? Concienciados de la condición perecedera de nuestra sustancia, no es de consuelo de lo que tenemos necesidad, sino de curación. Perseguimos el vacío, no por la verdad o falsedad que pueda encerrar, sino por sus virtudes terapéuticas. Si en Heidegger, el ser-ahí siente necesidad de la cura frente a la angustia del ser en el mundo, en Cioran la cura toma su necesidad del sufrimiento del ser-ahí que adquiere por su condición existenciaria de ser en el mundo. Con el vacío se realiza una cura, se toma conciencia de la no-realidad de las cosas, se percibe la inanidad de todas las verdades, se desengaña uno de la ilusión de suponer que algo existe y, al final, aporta la única esperanza esencial libre de artificios: la liberación del sufrimiento.

Cioran marca diferencias entre la nada tradicional, heredera del infierno cristiano, y el vacío purificador, auténtica experiencia metafísica. La experiencia liberadora del vacío proporciona una verdadera lección de abdicación frente a nuestros peores impulsos, dispensa un soplo sofocador del sufrimiento que se 
experimenta tanto en la hipótesis del ser como en la hipótesis del no ser, puesto que tanto los entes como las apariencias de entes hacen sufrir lo mismo. La hipótesis de la vacuidad, por otro lado, presenta una ventaja mayor respecto a la nada, pues desvela con mayor claridad la desmesura del sufrimiento y la inanidad de sus causas. Sólo mediante los accesos de lucidez de la conciencia, cuando ésta despierta ante la atrocidad de la existencia, percibe la ilusión dolorosa que atenaza a los seres. Sólo los hombres que buscan, los que han despertado y alcanzado la iluminación han podido convertirse en virtuosos del drama interior, del malestar espiritual que provoca el descoyuntamiento entre la sustancia y la vacuidad, o, más precisamente, como dice Cioran, entre los simulacros de una y de otra.

Sin embargo, mientras la búsqueda de la liberación está justificada en las filosofías orientales que son portadoras de las teorías de la transmigración, a fin de poner término a un vagabundeo indefinido del yo y alcanzar el nirvana, ¿estaría esa búsqueda justificada en quienes somos incrédulos de la transmigración? En nosotros, la búsqueda de la liberación se fija otras metas. No es el cese de una ronda interminable de diferentes existencias, de nacimientos y muertes, sino el cese del dolor de nuestra única, ínfima e inane existencia. Pero, frente a una existencia tan nimia e irreal, ¿por qué nos molestamos en liberarnos de una nadería? ¿Qué sentido tiene perseguir una irrealidad en un mundo que ya es irreal? Pese a esta aparente inconsecuencia, Cioran justifica la búsqueda de la liberación a través de la hipótesis del vacío con el siguiente argumento:

Encontrar que todo carece de fundamento y no acabar ahí, esta aparente inconsecuencia no es tal: llevada a su extremo, la percepción del vacío coincide con la percepción del todo, con la entrada en el todo. Por fin se comienza a ver, ya no se anda a tientas, uno se cerciora, se reafirma. Si existe una esperanza de salvación fuera de la fe, hay que buscarla en esa facultad de enriquecerse al contacto con la irrealidad.

Incluso si la experiencia del vacío no fuese más que un engaño, merecería la pena ser intentada. Lo que se propone, lo que intenta, es reducir a nada la vida y la muerte, y esto con un único propósito de hacérnoslas soportables. Si a veces lo logra, ¿qué más podemos desear? ${ }^{21}$

${ }^{21}$ Ibid., pág. 95. 


\section{Conclusiones}

Como puede inferirse de lo expresado, la respuesta de Cioran frente al problema del dolor de la vida supone un itinerario de medidas que van desde la adhesión a la música, la ética del desapego, la purga de la conciencia y la experiencia del vacío. En este sentido, Cioran aporta una respuesta positiva al problema del sufrimiento que, aun siendo indesarraigable, al menos puede ser transfigurado y convertido en fuente de grandes alegrías.

\section{Bibliografía}

Cioran, E.M. (2000). La tentación de existir, Madrid: Taurus.

- (1996). El libro de las quimeras, Barcelona: Tusquets.

- (1996). En las cimas de la desesperación, Barcelona: Tusquets.

— (1996). Conversaciones, Barcelona: Tusquets.

- (2000). El aciago demiurgo, Madrid: Taurus.

— (1995). Del inconveniente de haber nacido, Madrid: Taurus.

- (1993). La caída en el tiempo, Barcelona: Tusquets.

Heidegger, M. (1993). Ser y tiempo, Barcelona: Planeta-De Agostini.

Simmel, G. (2004). Intuición de la vida, La Plata (Argentina): Terramar Ediciones.

Recibido: 10/12/2019

Aceptado: 24/3/2020

Este trabajo se encuentra bajo una licencia de Creative Commons Reconocimiento-

NoComercial-SinObraDerivada 4.0 